\title{
Acceptability of Tenofovir Gel as a Vaginal Microbicide Among Women in a Phase I Trial: A Mixed-Methods Study
}

\author{
ROCHELLE K. ROSEN, Ph.D., ${ }^{1}$ KATHLEEN M. MORROW, Ph.D., ${ }^{1,2}$ \\ ALEX CARBALLO-DIÉGUEZ, Ph.D., ${ }^{3}$ JOANNE E. MANTELL, M.S.P.H., Ph.D., ${ }^{3}$ \\ SUSIE HOFFMAN, Dr. P.H., ${ }^{3}$ FANG GAI, M.P.H., ${ }^{4}$ LISA MASLANKOWSKI, M.D., ${ }^{5}$ \\ WAFAA M. EL-SADR, M.D., M.P.H., ${ }^{6}$ and KENNETH H. MAYER, M.D. ${ }^{1,2,7}$
}

\begin{abstract}
Objectives: In this phase I safety trial of tenofovir gel, a candidate vaginal microbicide for human immunodeficiency virus (HIV) prevention, a mixed-methods design was used to gather acceptability data among women participants. The impact of acceptability factors on use of the gel and the relationship between qualitative and quantitative acceptability data are explored.

Methods: Participants included low-risk, HIV-uninfected, and clinically stable HIV-infected women. Participants were enrolled into cohorts stratified by HIV serostatus, sexual activity, gel concentration, and frequency of use. Quantitative data were collected via interviewer-administered structured questionnaires. Qualitative data were collected via semistructured small group discussions.

Results: Although 94\% of participants stated they would "probably" or "definitely" use tenofovir gel, a range of responses emerged on multiple domains relevant to microbicide acceptability during the qualitative discussions. Lubrication, leakage, sexual pleasure, and the possibility of covert use were central to women's qualitative assessments of tenofovir gel.

Conclusions: Quantitative results indicate that tenofovir vaginal gel was acceptable to almost all users, while qualitative findings indicate that acceptability is complex, varies

\footnotetext{
${ }^{1}$ The Miriam Hospital, Providence, Rhode Island.

${ }^{2}$ The Warren Alpert Medical School of Brown University, Providence, Rhode Island.

${ }^{3}$ HIV Center for Clinical \& Behavioral Studies, NYS Psychiatric Institute, and Columbia University, New York, New York.

${ }^{4}$ Statistical Center for HIV / AIDS Research and Prevention, Fred Hutchinson Cancer Research Center, Seattle, Washington.

${ }^{5}$ University of Pennsylvania, Philadelphia, Pennsylvania.

${ }^{6}$ Columbia University and Harlem Hospital Center, New York, New York.

${ }^{7}$ Fenway Community Health, Providence, Rhode Island

The content of this publication does not necessarily reflect the views or policies of the National Institute of Allergy ucts, or organizations imply endorsement by the U.S. government.

This study was supported by the HIV Prevention Trials Network and sponsored by the National Institute of Allergy and Infectious Diseases, National Institute of Child Health and Human Development, National Institute on Drug Abuse, National Institute of Mental Health, and Office of AIDS Research of the National Institutes of Health, U.S. Department of Health and Human Services (U01-AI-48016, U01-AI-48014, U01-AI-48040, U01-AI-46749, U01-AI46702, and CFAR P30-AI-42853). Study product was supplied by Gilead Sciences, Inc., Foster City, California.
} and Infectious Diseases or the HIV Prevention Trials Network, nor does mention of trade names, commercial prod-
\end{abstract}


among users, and is likely shaped by a variety of contextual factors that manufacturers will need to consider to optimize use-effectiveness. Because of the differences in the qualitative and quantitative responses, the authors argue that future trials of candidate microbicides should include strategic collection of mixed-methods microbicide acceptability data.

\section{INTRODUCTION}

$\mathbf{T}$ HE GLOBAL HIV EPIDEMIC increasingly affects women. ${ }^{1}$ For most, the only risk factor for becoming infected is the behavior of their male sexual partners. ${ }^{1}$ Condoms often are unacceptable and insufficiently used, ${ }^{2-4}$ gender-based power imbalances can make them difficult to negotiate, ${ }^{4-7}$ and religious beliefs, fertility needs, fear of implied infidelity, and preferences for sex without a barrier are challenges to their acceptability and use. Women-initiated HIV prevention methods are urgently needed, making the development of vaginal microbicides that reduce the likelihood of sexual transmission of HIV a major public health priority.

First-generation vaginal microbicides will most likely be topical gels inserted into the vagina with an applicator. A variety of microbicides is currently under development, and six have entered late-stage clinical trials. ${ }^{8-12}$ Initial product acceptability has been assessed in clinical trials, ${ }^{13-16}$ surveys of product attributes among potential users $^{17,18}$ and their partners, ${ }^{19}$ and studies that use over-the-counter (OTC) surrogates or placebo gel with presumed similar formulation and application characteristics as eventual products. ${ }^{20-23}$ Acceptability assessments in early clinical trials are especially important because their findings can influence further development of the product.

Here, we report on acceptability data among women participating in a phase I trial of tenofovir gel, a candidate microbicide that inhibits HIV reverse transcriptase. Details of the trial are reported elsewhere, ${ }^{24}$ as is acceptability among male partners of trial participants. ${ }^{25}$ This was the first human trial of a topical antiretroviral that specifically inhibits a necessary replication step in the HIV life cycle. Interest in this approach to HIV prevention has increased in recent years since efficacy trials of a topical surfactant (nonoxynyl-9) and a nonspecific inhibitor of HIV binding (cellulose sulfate) indicated that these two types of compounds were not protective and potentially increased HIV transmission in women who had frequent sexual exposures to HIV. Several larger-scale, expanded safety and proof-ofconcept trials of tenofovir gel are now underway, based in part on the safety, tolerability, and acceptability of this microbicide demonstrated in the study described in this paper.

\section{MATERIALS AND METHODS}

\section{Study design and protocol}

HIV Prevention Trials Network 050 (HPTN) was a multisite, phase I, open-label, dose and frequency study of $0.3 \%$ and $1.0 \%$ tenofovir vaginal gel. ${ }^{24}$ The primary study objectives were to assess safety, toxicity, and absorption of the product used vaginally by women at low risk for HIV infection and by HIV-infected women. The safety study found that adverse events tended to be mild and self-limited. ${ }^{24}$ A secondary objective of the study was to assess product acceptability using both quantitative and qualitative methods, which is reported here.

Cohorts were stratified by HIV serostatus and by sexual abstinence or activity (Table 1). Participants were recruited in three U.S. cities, New York, Philadelphia, and Providence, through community educational activities, advertisements, and word of mouth. Eligibility criteria included being 18-45 years of age and having regular menstrual cycles or being amenorrheic as a result of long-acting hormonal therapy, that is, progestins, such as Norplant (Wyeth-Ayerst, Philadelphia, PA). Sexually active women had to be in a mutually monogamous heterosexual relationship and have vaginal sex at least twice per week. Abstinent women refrained from having sex from 48 hours prior to the study enrollment visit until the day 14 follow-up visit. All participants underwent a consent process that was approved by local institutional review boards. Participants were reimbursed for study visits as follows: $\$ 50$ for each visit when they had a pelvic examination (e.g., screening visit, day $2-3$ visit, and day 7 visit), \$100 for each visit when they had a 
Table 1. HPTN 050 Cohort Progression and Data Collection

\begin{tabular}{|c|c|c|c|}
\hline & $\begin{array}{c}\text { Enrolled in } \\
\text { cohort } \\
\mathrm{n}=84\end{array}$ & $\begin{array}{c}\text { Completed } \\
\text { acceptability } \\
\text { assessment } \\
\text { (quantitative) } \\
\mathrm{n}=79\end{array}$ & $\begin{array}{c}\text { Participated in } \\
\text { small group } \\
\text { discussion } \\
\text { (qualitative) } \\
\mathrm{n}=40^{\mathrm{a}}\end{array}$ \\
\hline $\begin{array}{l}\mathrm{A}_{1} \text { Sexually abstinent, HIV-uninfected, } \\
0.3 \% \text { tenofovir gel, once daily } \mathrm{b}\end{array}$ & 12 & 12 & 0 \\
\hline $\begin{array}{l}\mathrm{A}_{2} \text { Sexually abstinent, HIV-uninfected, } \\
1.0 \% \text { tenofovir gel, once daily }\end{array}$ & 12 & 11 & 4 \\
\hline $\begin{array}{l}\mathrm{A}_{3} \text { Sexually abstinent, HIV-uninfected, } \\
0.3 \% \text { tenofovir gel, twice daily }\end{array}$ & 12 & 11 & 5 \\
\hline $\begin{array}{l}\mathrm{A}_{4} \text { Sexually abstinent, HIV-uninfected, } \\
1.0 \% \text { tenofovir gel, twice daily }\end{array}$ & 12 & 12 & 11 \\
\hline $\mathrm{B}^{\mathrm{c}}$ Sexually active, HIV-uninfected, $\mathrm{HPDF}^{\mathrm{d}}$ & 12 & 11 & 5 \\
\hline C Sexually abstinent, HIV-infected, HPDF & 12 & 12 & 9 \\
\hline$D^{c}$ Sexually active, HIV-infected, HPDF & 12 & 10 & 6 \\
\hline
\end{tabular}

aSmall group discussions included 11 sexually active women, of whom 6 were HIV infected and 5 were uninfected, and 29 abstinent women, of whom 9 were HIV infected and 20 were uninfected.

bOnce-daily applications occurred at bedtime; twice-daily applications in the morning and at bedtime. Sexually active participants inserted gel up to 2 hours prior to intercourse in lieu of one of the other doses.

cMale partners also enrolled; see Carballo-Diéguez et al. ${ }^{25}$

${ }^{\mathrm{d}} \mathrm{HPDF}$, highest practical dose and frequency: $1.0 \%$ tenofovir gel twice daily.

colposcopy (e.g., enrollment visit and day 14 visit), and $\$ 25$ for participation in the group interview. Additional inclusion/exclusion criteria are described elsewhere. ${ }^{24}$

\section{Study product and administration}

Tenofovir gel is a clear, transparent, and viscous gel prepackaged in single-dose tubes. Participants screwed the tube of product onto a polyethylene applicator, filled the applicator, and then inserted the gel; the applicator was disposed of after use. Women used the gel for 14 days between menstrual periods, either once or twice daily. Those assigned to once-daily dosing inserted the product at bedtime; those assigned to twice-daily dosing inserted it in the morning as well as at bedtime. Sexually active participants replaced one of those doses with one inserted not more than 2 hours before vaginal intercourse, at least 2 days a week. Adherence was assessed by an interviewer-administered questionnaire, and nonadherence was defined as 3 or more days of missed product use. ${ }^{24}$

\section{Acceptability data collection and analysis}

Acceptability data were collected using both qualitative and quantitative methodologies to (1) describe the range of user experiences, (2) explore the impact those experiences might have for wo- men in future trials and on use of the product once approved, and (3) examine the utility of mixed-method acceptability studies in microbicide clinical trials. In this mixed-method design, the qualitative data component was conducted as a follow-up to the quantitative acceptability assessment to help interpret the quantitative results and provide additional contextual acceptability data. A mixed-method design of this type has the specific benefit of providing insights that cannot be gathered from the quantitative data alone. ${ }^{26}$ The presentation of results deliberately mimics this methodology: quantitative data on a topic are presented first, followed by context and interpretations gathered from the qualitative data. No trends were noted within the quantitative data based on specific demographic characteristics.

In addition to trial-related experiences, acceptability assessment elicited women's thoughts about product acceptability in real life. Although responses about intentions for future use were limited by the context of a clinical trial protocol, they are also grounded in the attributes of, and user experiences with, an actual product and provide significant insight into the factors that affect eventual product acceptability and use.

\section{Quantitative data}

After completing the period of gel use in the study, women completed a quantitative accept- 
ability assessment where they were asked to rate vehicle-associated factors (e.g., color, smell, consistency), experiences during sex (e.g., effect on sexual pleasure, leakage, dryness, stickiness, wetness), overall likes and dislikes, likelihood of future use, desire for a microbicide that could be used covertly, and whether they would use it with or without a condom. All participants completed questionnaires independently from their male partners. Global acceptability was defined as the proportion of participants indicating they would probably or definitely use the product if it were available and they had reason to be worried about risk of HIV.

\section{Qualitative data}

Qualitative data were collected via small group discussions. Study protocol required that discussions be limited to a minimum of 2 participants to preclude individual interviews and standardize qualitative data collection. Fifteen small groups of between 2 and 5 participants were conducted with a total of 40 women. Discussions explored women's experiences applying the gel on a daily basis and, for those in the sexually active cohorts, having intercourse while using the gel.

A detailed topic guide was used and covered daily use in nonsexual contexts (e.g., application and leakage, how it felt to use the product, personal hygiene during product use). Sexually active participants also explored how the product felt during sex: leakage before, during, and after; lubricating/drying effects; and attitudes about required condom use. Other issues included perceived partner responses, attitudes regarding vehicle-associated factors, potential covert use of study product and microbicides in general, and future likelihood of use. All discussions were audiotaped and subsequently transcribed.

A qualitative data-coding scheme was developed based on the topic guide, the study protocol, and prior acceptability research; codes were then expanded based on content analysis of the transcripts. Two coders, one from the collection site and one from another site, coded each transcript to ensure completeness of coding. Discrepancies between coders were identified, and consensus was reached. The mutually agreed upon codes were entered into the transcripts using QSR NVivo qualitative software (QSR International Pty Ltd., Melbourne, Australia). Data were analyzed for major themes, and relationships with other themes and quantitative variables.

\section{RESULTS}

\section{Participant characteristics}

Eighty-four women participated in the clinical trial. Seventy-nine participants completed quantitative acceptability assessments; of those, 40 also participated in the qualitative discussions. There were no significant demographic differences between those who completed the quantitative assessment only and those who also attended the qualitative discussions (Table 2).

\section{Product acceptability}

When asked in the quantitative assessment: "If you had reason to be worried about getting or passing HIV and this gel were available, how likely would you be to use it?" 60 (76\%) women indicated they would definitely use it, $14(18 \%)$ indicated they would probably use it, 3 (4\%) indicated they would probably not use it, and 2 (3\%) said they would definitely not use it. Thus, overall, $94 \%$ said they definitely or probably would use the product, indicating that the gel was highly acceptable (Table 3). There were no noteworthy differences in the quantitative acceptability results among women who participated in the qualitative discussions vs. those who did not. The qualitative discussions, however, revealed considerable variability about factors related to acceptability.

Perceptions of product and its application. A high proportion of all women indicated on the quantitative assessment that they liked the gel's color, smell, and consistency (Table 3). During qualitative discussions, participants said they perceived the gel prior to insertion to be clear, colorless, and odorless, qualities they often praised. For example, one described the gel's scent as "comfortable" and "not strong." Most participants found the consistency acceptable (e.g., "just the right texture," "not too thick, not too thin"), although some thought a thicker consistency would improve it. Most participants reported that the product was "easy" or "very easy" to use, in part because the application process mirrored that of other vaginal products they had used. Some participants reported that the application process required privacy and time-at least 5 minutes, according to 1 participant.

Responses to daily use. Daily use leakage (as opposed to leakage with sex) was not measured in 
Table 2. Patient Demographics

\begin{tabular}{|c|c|c|}
\hline & $\begin{array}{l}\text { Completed follow-up acceptability assessment } \\
\qquad(\mathrm{n}=79)\end{array}$ & $\begin{array}{l}\text { Participated in small group discussions } \\
\qquad(\mathrm{n}=40)\end{array}$ \\
\hline Latina & $n=15(19 \%)$ & $n=10(25 \%)$ \\
\hline African American & 4 & 3 \\
\hline White & 1 & 1 \\
\hline Other & 10 & 6 \\
\hline Non-Latina & $n=64(81 \%)$ & $n=30(70 \%)$ \\
\hline African American & 31 & 15 \\
\hline White & 27 & 13 \\
\hline Asian & 2 & 1 \\
\hline Multiraciala & 2 & 0 \\
\hline Other & 2 & 1 \\
\hline Mean age & 36.2 years & 36.0 years \\
\hline \multicolumn{3}{|l|}{ Highest level of education } \\
\hline Less than high school & $23(29 \%)$ & $12(30 \%)$ \\
\hline High school diploma & $24(30 \%)$ & $11(28 \%)$ \\
\hline Some college & $17(22 \%)$ & $10(25 \%)$ \\
\hline College degree & $12(15 \%)$ & $7(18 \%)$ \\
\hline Some postcollege & $1(1 \%)$ & 0 \\
\hline Graduate/professional degree & $2(3 \%)$ & 0 \\
\hline \multicolumn{3}{|l|}{ Type of student } \\
\hline Full-time student & $6(8 \%)$ & $3(8 \%)$ \\
\hline Part-time student & $7(9 \%)$ & $3(8 \%)$ \\
\hline Not a student & $66(84 \%)$ & $34(85 \%)$ \\
\hline \multicolumn{3}{|l|}{ Employment status } \\
\hline Full-time employment & $16(20 \%)$ & $6(15 \%)$ \\
\hline Part-time employment & $12(15 \%)$ & $6(15 \%)$ \\
\hline Unemployed & $50(63 \%)$ & $28(70 \%)$ \\
\hline Other & $1(1 \%)$ & 0 \\
\hline \multicolumn{3}{|l|}{ Household income } \\
\hline$<\$ 6,000 /$ year & $16(20 \%)$ & $10(25 \%)$ \\
\hline$\$ 6,000-\$ 11,999 /$ year & $35(44 \%)$ & $20(50 \%)$ \\
\hline$\$ 12,000-\$ 29,999 /$ year & $17(22 \%)$ & $5(13 \%)$ \\
\hline$\$ 30,000-\$ 59,999 /$ year & $9(11 \%)$ & $4(10 \%)$ \\
\hline$>\$ 60,000 /$ year & $2(3 \%)$ & $1(3 \%)$ \\
\hline
\end{tabular}

a2 participants identified themselves as having more than one ethnicity; one participant identified herself as "American Indian Alaska native, black/African American," another identified as "Native Hawaiian/other Pacific Islander, French."

the quantitative assessment. During qualitative discussions, however, leakage of the product after insertion was commonly reported. Several women described the gel as "messy," "sticky," or "gooey," which they did not find acceptable. The amount of leakage and the degree to which participants considered it a nuisance, however, varied considerably. Some indicated the leakage was significant, like a "waterfall." It left them feeling "moist all the time." A sexually abstinent participant described leakage as being similar to when semen drips out of her vagina after her partner ejaculates; other women agreed. One participant reported that leakage was greater when she was on her feet and moving around after application as opposed to lying down following insertion of the product. In contrast, several indicated that they did not find the product messy. Approximately twice as many participants identified the product as leaking and messy than those who did not.

Because of product leakage, several women changed their hygiene habits by wiping more frequently after urination or cleaning themselves more thoroughly. Similarly, panty liners were provided by study for participants' use, and individual women responded differently to this, with some feeling a need to change them more frequently and others hardly needing them.

Responses to use during sex. Table 3 summarizes quantitative data related to gel use during sex. Most participants (90\%) indicated either that the gel increased their sexual pleasure or that it made no difference. Similarly, most $(86 \%)$ felt the product increased their male partner's sexual pleasure or that it made no difference. In discussions, some sexually active women reported leakage of gel 
Table 3. Results from Follow-Up Acceptability Assessment: Quantitative Acceptability Results by Sexually Abstinent and Sexually Active Participants $(N=79)$, Female Participant Experiences While Using Tenofovir Gel During Sex $(N=22)$, and Effects of Tenofovir Gel on Sexual Pleasure $(N=22)^{\mathrm{a}}$

\begin{tabular}{|c|c|c|c|c|c|}
\hline & & $\begin{array}{c}\text { Sexually } \\
\text { abstinent } \\
\text { cohorts } \\
\mathrm{n}=58\end{array}$ & & $\begin{array}{c}\text { Sexually } \\
\text { active } \\
\text { cohorts } \\
\mathrm{n}=21\end{array}$ & $\begin{array}{c}\text { Total } \\
\mathrm{n}=79\end{array}$ \\
\hline Overall liked gel & & $45(78 \%)$ & & $17(81 \%)$ & $62(78 \%)$ \\
\hline Liked somewhat/a lot gel's & & & & & \\
\hline Color & & $53(91 \%)$ & & $21(100 \%)$ & $74(94 \%)$ \\
\hline Smell & & $46(79 \%)$ & & $19(90 \%)$ & $65(82 \%)$ \\
\hline Consistency & & $42(72 \%)$ & & 17 (81\%) & 59 (75\%) \\
\hline Likelihood of $u^{b} e^{b}$ & & & & & \\
\hline Definitely/probably use & & $55(95 \%)$ & & $19(90 \%)$ & $74(94 \%)$ \\
\hline Definitely/probably not use & & $3(5 \%)$ & & $2(10 \%)$ & $5(6 \%)$ \\
\hline Of the sexually active participan & 22) & & & & \\
\hline Did the gel & & & Yes & & No \\
\hline cause an interruption in sex & er to apply? & & $1(5 \%)$ & & $21(95 \%)$ \\
\hline make sex feel more wet? & & & $19(86 \%)$ & & $3(14 \%)$ \\
\hline dry out during sex? & & & $1(5)$ & & $21(95)$ \\
\hline get sticky during sex? & & & $5(23)$ & & $17(77)$ \\
\hline leak out & & & & & \\
\hline before sex? & & & $9(41)$ & & $13(59)$ \\
\hline during sex? & & & $11(50)$ & & $11(50)$ \\
\hline after sex? & & & $15(68)$ & & $7(32)$ \\
\hline & $\begin{array}{c}\text { Strongly } \\
\text { agree } \\
\text { n (\%) }\end{array}$ & $\begin{array}{c}\text { Agree } \\
\text { somewhat } \\
\mathrm{n}(\%)\end{array}$ & $\begin{array}{c}\text { No } \\
\text { difference } \\
\mathrm{n}(\%)\end{array}$ & $\begin{array}{c}\text { Disagree } \\
\text { somewhat } \\
\text { n }(\%)\end{array}$ & $\begin{array}{c}\text { Strongly } \\
\text { disagree } \\
\mathrm{n}(\%)\end{array}$ \\
\hline Overall, I felt that using the gel & & & & & \\
\hline increased my sexual pleasure & $5(23)$ & $5(23)$ & $10(45)$ & $2(9)$ & $0(0)$ \\
\hline decreased my sexual pleasure & $1(5)$ & $1(5)$ & $8(36)$ & $1(5)$ & $11(50)$ \\
\hline increased his sexual pleasure & $6(27)$ & $5(23)$ & $8(36)$ & $2(9)$ & $1(5)$ \\
\hline decreased his sexual pleasure & $1(5)$ & $3(14)$ & $8(36)$ & $3(14)$ & $7(32)$ \\
\hline
\end{tabular}

aThese data come from 21 women in sexually active cohorts and from 1 woman in an abstinent cohort who reported having sex while using this product.

b"If you had reason to be worried about getting or passing HIV and this gel were available, how likely would you be to use it?"

during sex. Here, too, there was individual variation: some women reported leakage not much greater than what they usually experience with sex, and others mentioned it would not pose a problem because they normally wash after sex. Still others viewed the gel as making sex "messy." Most participants reported the gel made them feel more lubricated during sex, although responses to this additional lubrication varied widely. Some said it enhanced the sexual experience: "It made sex a little more enjoyable because it was moister"; "We didn't have to use extra lube because the gel already did that for us." A few, however, reported too much lubrication, which was not pleasurable: "this was a little more wet, and I . . like it drier. . . . I would've preferred it to be more ... drier, you know?"

The amount of time that elapsed after product application also seemed to affect how "slippery" sex felt. One participant reported that she had sex after the prescribed 2-hours postgel insertion window and noted that she was "not as wet as you would be when you first put it in." This was preferable to the discomfort she had when applying the gel closer to coitus. Finally, a few women said there was little change in lubrication levels.

Condom use and acceptability. When asked, "Would you use the gel alone or only with a condom?" 26 (33\%) of the women said they would use the gel alone, and $53(67 \%)$ said they would use it only with a condom. Of the sexually active participants, $3(14 \%)$ said they would use the gel alone, and $18(86 \%)$ said they would use the gel only with a condom. Of the 22 HIV-positive participants, $8(36 \%)$ said they would use the gel 
alone, and 14 (64\%) said they would use it only with a condom. In a discussion, one participant said, "To be on the safe side and if this is a product to help ... prevent HIV, I would use them both. I would use the gel and I would use the condom." In the qualitative data, many condom discussions centered on the requirement to use them throughout the trial; this fact alone made sex different for many participants, as only a few reported regular condom use prior to study participation. Many complained about using condoms or reported that their partners did not like them, although some noted that the gel made condom use more appealing. Some participants assumed that an efficacious gel would be an alternative to condoms: "If my partner didn't really enjoy using condoms, I would still have something that I could use to protect the both of us."

Covert use. In the quantitative assessment, 56 women $(71 \%)$ said they would prefer a microbicide that could not be noticed by a sex partner, whereas $15(19 \%)$ said it would not matter, and 8 $(10 \%)$ said they would not prefer a product that could not be noticed by a sex partner. In the discussions, women generally thought that certain characteristics of the gel, including its lack of color and odor, made it less likely to be noticed by a partner. Some noted that a woman could attribute additional lubrication from microbicide use to lubricant use. At the same time, many women believed that regular partners might detect the increase in lubrication associated with product use: "The gel, it's like really wet . . . if your partner knows you ... he will be able to tell the difference." Others thought that unfamiliar, or new, partners would not detect the increased wetness or that they could explain it if they did: "Honestly, I could use it with a man and what he would think was . . 'this girl is just wet!'"

Although many women indicated that, in their own relationships, they would tell their partner if they were using such a product, there was a strong sense that having a product that could be used covertly would be useful to women generally. For casual relationships, participants believed that it was the woman's choice as to whether or not to inform her partner of product use. Some women suggested that there were circumstances, even in established relationships, where it would be acceptable to use the product covertly, including when a male partner would not use condoms.
HIV-infected women. HIV-infected women wanted a microbicide that protects their partners from infection and themselves from reinfection, saying microbicides could allay their fears about infecting other partners. However, they also questioned whether a microbicide would be effective for a person with "full-blown AIDS." Interestingly, 1 participant attributed changes in her viral load, in part, to product use. Such changes are not supported by the clinical safety data, and the woman did not experience any major fluctuation in her plasma viral load. ${ }^{24}$

\section{DISCUSSION}

Although results indicate high acceptability of tenofovir gel based on quantitative measures, a wider range of product ratings emerged qualitatively, indicating some situations in which behavioral and contextual factors altered degrees of acceptability. Whereas participants supported the idea of a women-controlled method for HIV prevention and expressed satisfaction with many characteristics of the gel, leakage during and after sex was unacceptable for some.

Quantitative and qualitative acceptability data were constrained, necessarily, by the study protocol, including the enrollment of more abstinent than active participants, the requirement that male partners of active participants wear condoms during vaginal intercourse, and requirements to refrain from oral and anal sex, use of sex toys, and use of other vaginal products. Although only half of the enrolled women participated in small group discussions, there were no significant demographic or quantitative acceptability differences overall (e.g., likes and dislikes of gel, leakage) between those who did and did not participate in the qualitative discussions.

The acceptability of tenofovir gel as a microbicide will likely be closely related to its perceived impact on sexual pleasure, ${ }^{27}$ a domain that intersects strongly with product leakage and lubricating quality during sex. Themes raised during the qualitative assessments about the interaction of product leakage and sexual pleasure included (1) how tolerable was leakage during or after sex, (2) how personal preferences for sexual lubrication interact with the product and together influence sexual pleasure, and (3) the relationship between lubrication and perceived partner awareness of gel use. Similar themes are relevant to covert use, 
including relationship factors. These include how well the partner knows the woman's typical physical responses during sex, as well as the status of the relationship. For some, microbicides may be appropriate with new or casual partners who may not notice a difference in lubrication, a finding supported by other qualitative investigations of microbicide acceptability. ${ }^{14}$

Messiness and leakage of the gel in relation to daily use were important themes in the small group discussions, and these warrant further study. Other microbicide acceptability studies have also noted significant product leakage, necessitating more demanding hygiene requirements to compensate. ${ }^{14,15}$ Phase II extended safety and acceptability testing of both once-daily and coitally-dependent tenofovir gel is underway, and further acceptability studies will significantly advance our knowledge. To enhance adherence to study protocols, potential participants will need to be educated to expect and manage these findings. It is also possible that women may be paying increased attention to their bodies as a result of trial participation and frequent application of the product. Careful mixed-methods data collection in expanded safety and efficacy trials will be important for clarifying these issues and anticipating acceptability of tenofovir gel.

The perception by $1 \mathrm{HIV}$-infected participant that the use of the gel was associated with fluctuations in her viral load illustrates that user perceptions of product effects, whether or not they are clinically supported, can influence acceptability, a point noted in other research as well. ${ }^{28}$ This may be particularly relevant with products like tenofovir that have antiretroviral activity. Women's perceptions of a microbicide's effects and their reasons for ascribing such effects, even where none exist, must be understood.

The acceptability of an investigational product will be inevitably influenced by the context of the trial itself, including protocol requirements for specific sexual behavior (e.g., abstinence vs. protocol-specific minimal frequency of sex) and consistent male condom use in sexually active cohorts. Because no vaginal microbicide candidate has yet been shown to be effective, within-trial assessments provide the only opportunity to learn about the experiences of women and men who have used these products. Protocol-mandated sexual and hygiene requirements and restrictions (e.g., no douching during the study) may have influenced comfort or acceptability. Not all protocol demands, however, limit knowledge gained. There are advantages to trial-related investigations of microbicide acceptability, including how daily use of product during a clinical trial differs from likely coitally-dependent use in real life or how condom use influences microbicide acceptability.

Because of the requirement for condom use, it is unclear to what extent participant acceptability ratings were independently associated with product use vs. the combination of product and male condom use during sex. Most participants, however, indicated a desire to use the gel with a condom. As condom use will be a likely recommendation for first-generation microbicides, ${ }^{29}$ which are unlikely to be $100 \%$ effective, condombased acceptability data are highly relevant. Further, this aspect of acceptability, which has previously been thought of as a limitation of clinical trial data, may actually be a significant acceptability factor that should continue to be assessed. Efficacy trials will invariably mandate consistent condom use, but as they will be enrolling highrisk women, lapses should be captured during follow-up visits, such that microbicide use with and without condoms can be studied in greater detail.

A limitation of the study is that because it was a phase I safety trial it necessarily enrolled a small number of participants. Further, only half of those were able to participate in qualitative groups. This limits in-depth analysis across demographic variables. Additionally, because of the small sample size and the enrollment criteria, these data may not be generalizable to the broader population of women who will most want and use a vaginal microbicide.

One of the strengths of qualitative data collection in clinical trials is the ability to focus on the entire process of product use, from application through sexual activity. For example, collecting data reflective of participants' application learning curves, comfort with the applicator, and time and privacy needs is a strength of acceptability data obtained from daily use in clinical trials precisely because participants have so much experience with the application process during that time. Participant comments that the gel made condom use more appealing, coupled with reports by the majority of participants that tenofovir gel increased or made no difference in their sexual pleasure, suggest that microbicide use 
could be promoted as a way to motivate condom use.

\section{CONCLUSIONS}

Women indicated a high likelihood of using tenofovir gel if it were available as a microbicide for reducing the likelihood of HIV infection. The utility of conducting mixed-methods studies of microbicide acceptability during clinical trials is demonstrated by the differences between the qualitative and quantitative data reported here. This suggests that effective and integrated data collection methods need to be considered early in planning future trials and points to the importance of qualitative data for elucidating user opinions about product use acceptability and likely patterns of use. The study findings also demonstrate a need to expand the quantitative acceptability assessments in order to capture more details on factors related to acceptability.

Acceptability remains a strongly subjective construct, continually shaped by individual opinions that are themselves likely to be formed by a variety of factors, including physical well-being, sexual pleasure, partner and relationship factors, and other contextual and cultural norms. Future acceptability assessments might profitably employ both quantitative and qualitative methods but should do so in parsimonious ways most applicable to the appropriate phase in product development ${ }^{30,31}$ Additionally, there remains a strong need to develop robust acceptability assessment tools that can be standardized for use across microbicide trials, allowing for increased knowledge by creating an opportunity for metaanalyses across studies to delineate important themes that may increase the acceptance of new microbicides ${ }^{30,31,32}$

\section{REFERENCES}

1. UNAIDS. Report on the global AIDS epidemic: UNAIDS, 2006.

2. Mason TH, Foster SE, Finlinson HA, et al. Perspectives related to the potential use of vaginal microbicides among drug-involved women: Focus groups in three cities in the United States and Puerto Rico. AIDS Behav 2003;7:339.

3. Exner TM, Seal DW, Ehrhardt AA. A review of HIV interventions for at-risk women. AIDS Behav 1997;1:93.
4. Sobo EJ. Choosing unsafe sex: AIDS-risk denial among disadvantaged women. Philadelphia: University of Pennsylvania Press, 1995.

5. Green G, Pool R, Harrison S, et al. Female control of sexuality: Illusion or reality? Use of vaginal products in southwest Uganda. Soc Sci Med 2001;52:585.

6. Heise LL, Elias C. Transforming AIDS prevention to meet women's needs: A focus on developing countries. Soc Sci Med 1995;40:931.

7. Population Council. The case for microbicides: A global priority. Population Council, Inc., New York, NY, and International Family Health, 2000.

8. Harrison PF, Rosenberg Z, Bowcut J. Topical microbicides for disease prevention: Status and challenges. Clin Infect Dis 2003;36:1290.

9. Elias C, Coggins C. Acceptability research on femalecontrolled barrier methods to prevent heterosexual transmission of HIV: Where have we been? Where are we going? J Womens Health Gend Based Med 2001; 10:163.

10. Microbicide News Highlights. Microbicide Q 2004;2:19.

11. Alliance for Microbicide Development News Digest, June 2, 2006, Vol. 7, No. 20. Available at www.microbicide.org Accessed June 2, 2006.

12. Global Campaign for Microbicides. About microbicides: The science: Products in the pipeline. Available at www.global-campaign.org/products_in_the_pipeline. $\mathrm{htm}$ Accessed June 2, 2006.

13. Bentley ME, Morrow KM, Fullem AM, et al. Acceptability of a novel vaginal microbicide during a safety trial among low-risk women. Fam Plann Perspect 2000;32:184.

14. Morrow K, Rosen R, Richter L, et al. The acceptability of an investigational vaginal microbicide, PRO $2000 \mathrm{Gel}$, among women in a phase I clinical trial. I Womens Health 2003;12:655.

15. Bentley ME, Fullem AM, Tolley EE, et al. Acceptability of a microbicide among women and their partners in a 4-country phase I trial. Am J Public Health 2004; 94:1159.

16. Coggins C, Blanchard K, Alvarez F, et al. Preliminary safety and acceptability of a carrageenan gel for possible use as a vaginal microbicide. $\underline{\text { Sex Transm Infect }}$ 2000;76:480.

17. Darroch JE, Frost JJ. Women's interest in vaginal microbicides. Fam Plann Perspect 1999;31:16.

18. Holt BY, Morwitz VG, Ngo L, et al. Microbicide preference among young women in California. I Womens Health 2006;15:281.

19. Coggins C, Blanchard K, Friedland B. Men's attitudes towards a potential vaginal microbicide in Zimbabwe, Mexico and the USA. Reprod Health Matters 2000;8:132.

20. Hammett TM, Mason TH, Joanis CL, et al. Acceptability of formulations and application methods for vaginal microbicides among drug-involved women: Results of product trials in three cities. Sex Transm Dis 2000;27:119.

21. Coetzee N, Blanchard K, Ellertson C, Hoosen AA, Friedland B. Acceptability and feasibility of Micralax 
applicators and of methyl cellulose gel placebo for large-scale clinical trials of vaginal microbicides. AIDS 2001;15:1837.

22. Coggins C, Elias CJ, Atisook R, et al. Women's preferences regarding the formulation of over-the-counter vaginal spermicides. AIDS 1998;12:1389.

23. Program for Appropriate Technology in Health. Need for continued evaluation of microbicide applicators for use in low-resource settings. Seattle, WA: PATH, 2002. (Also, Current Opinion in Obstetrics and Gynecology, 2003;15:371. Need for continued evaluation of microbicide applicators for use in low-resource settings. Report to USAID. Seattle WA: Appropriate Technology in Health, 2002).

24. Mayer KH, Maslankowski LA, Gai F, et al. Safety and tolerability of tenofovir vaginal gel in abstinent and sexually active HIV-infected and uninfected women. AIDS 2006;20:543.

25. Carballo-Diéguez A, Balan IC, Morrow K, et al. Acceptability of tenofovir gel as a vaginal microbicide by U.S. male participants in a phase I clinical trial (HPTN 050). AIDS Care 2007;19:1026.

26. Ulin PR, Robinson ET, Tolley EE. Qualitative methods in public health: A field guide for applied research. San Francisco, CA: Jossey-Bass, 2005.

27. Severy LJ, Newcomer S. Critical issues in contraceptive and STI acceptability research. I Social Issues 2005;61:45.
28. Mantell JE, Morar NS, Myer L, Ramjee G. "We have our protector": Misperceptions of protection against HIV among participants in a microbicide efficacy trial. Am J Public Health 2006;96:1073.

29. Foss AM, Vickerman PT, Heise L, Watts CH. Shifts in condom use following microbicide introduction: Should we be concerned? AIDS 2003;17:1227.

30. Morrow KM. Key methodological issues in behavioral research on microbicides. Paper presented at The NIH Microbicide Workshop: Behavioral \& Social Science Issues in Microbicide Research, National Institutes of Health, September 23, 2005; Bethesda, MD.

31. Morrow KM, Ruiz MS. Assessing microbicide acceptability: A comprehensive and integrated approach. AIDS Behav., June 26, 2007. (Epub ahead of print). PMID: 17592763.

32. Mantell JE, Myer L, Carballo-Dieguez A, et al. Microbicide acceptability research: Current approaches and future directions. Soc Sci Med 2005;60:319.

Address reprint requests to: Rochelle K. Rosen Centers for Behavioral and Preventive Medicine The Miriam Hospital One Hoppin Street, Suite 500 Providence, RI 02903

E-mail: Rrosen@lifespan.org 


\section{This article has been cited by:}

1. Francisca Rodrigues, Maria João Maia, José das Neves, Bruno Sarmento, Maria Helena Amaral, Maria Beatriz P.P. Oliveira. 2015. Vaginal suppositories containing Lactobacillus acidophilus : development and characterization. Drug Development and Industrial Pharmacy 41, 1518-1525. [CrossRef]

2. N. Yao, Q. Zeng, N.X. Zhong, D.X. Li, L.A. Huang, M.Y. Shao, H.Y. Ruan. 2015. Use of partial least squares path modelling to assess the willingness of Chinese female sex workers to participate in a microbicide trial. Public Health 129, 1187-1193. [CrossRef]

3. Sophia G. Antimisiaris, Spyridon Mourtas. 2015. Recent advances on anti-HIV vaginal delivery systems development. Advanced Drug Delivery Reviews 92, 123-145. [CrossRef]

4. Rochelle K. Rosen, Jacob J. van den Berg, Sara E. Vargas, Natali Senocak, Julia G. Shaw, Robert W. Buckheit, Kelley Alison Smith, Kate Morrow Guthrie. 2015. Meaning-making matters in product design: users' sensory perceptions and experience evaluations of long-acting vaginal gels and intravaginal rings. Contraception . [CrossRef]

5. Rita Palmeira-de-Oliveira, Paulo Duarte, Ana Palmeira-de-Oliveira, José das Neves, Maria Helena Amaral, Luiza Breitenfeld, José Martinez-de-Oliveira. 2015. Women's experiences, preferences and perceptions regarding vaginal products: Results from a cross-sectional web-based survey in Portugal. The European Journal of Contraception \& Reproductive Health Care 20, 259-271. [CrossRef]

6. Mitzy Gafos, Robert Pool, Misiwe Adelaide Mzimela, Hlengiwe Beauty Ndlovu, Sheena McCormack, Jonathan Elford. 2015. Communication About Microbicide Use Between Couples in KwaZulu-Natal, South Africa. AIDS and Behavior 19, 832-846. [CrossRef]

7. Flash Charlene A., Stone Valerie E., Mitty Jennifer A., Mimiaga Matthew J., Hall Kathryn T., Krakower Douglas, Mayer Kenneth H.. 2014. Perspectives on HIV Prevention Among Urban Black Women: A Potential Role for HIV Pre-Exposure Prophylaxis. AIDS Patient Care and STDs 28:12, 635-642. [Abstract] [Full Text HTML] [Full Text PDF] [Full Text PDF with Links]

8. Jennifer L. Brown, Jessica M. Sales, Ralph J. DiClemente. 2014. Combination HIV Prevention Interventions: The Potential of Integrated Behavioral and Biomedical Approaches. Current HIVIAIDS Reports 11, 363-375. [CrossRef]

9. Ian McGowan, Charlene Dezzutti, Lisa RohanThe Development of Rectal Microbicides for HIV-1 Prevention 331-375. [CrossRef]

10. Cameron Ball, Kim WoodrowElectrospun Fibers for Microbicide Drug Delivery 459-507. [CrossRef]

11. Elizabeth Tolley, Barbara Friedland, Mitzy Gafos, Rivet Amico, Lut Van Damme, Cynthia Woodsong, Kathleen MacQueen, Leila Mansoor, Sheena McCormackSocioeconomic and Behavioral Factors Influencing Choice, Adherence, and Success of Microbicide Formulations 569-628. [CrossRef]

12. Michele Lanham, Rose Wilcher, Elizabeth T Montgomery, Robert Pool, Sidney Schuler, Rachel Lenzi, Barbara Friedland. 2014. Engaging male partners in women's microbicide use: evidence from clinical trials and implications for future research and microbicide introduction. Journal of the International AIDS Society 17. . [CrossRef]

13. José das Neves, Rita Palmeira-de-Oliveira, Ana Palmeira-de-Oliveira, Francisca Rodrigues, Bruno SarmentoVaginal Mucosa and Drug Delivery 99-132. [CrossRef]

14. Annalene Nel, Wouter Haazen, Jeremy Nuttall, Joseph Romano, Zeda Rosenberg, Neliëtte van Niekerk. 2014. A safety and pharmacokinetic trial assessing delivery of dapivirine from a vaginal ring in healthy women. AIDS 28, 1479-1487. [CrossRef]

15. Claire J. Forbes, Clare F. Mccoy, Diarmaid J. Murphy, A. David Woolfson, John P. Moore, Abbey Evans, Robin J. Shattock, R. Karl Malcolm. 2014. Modified Silicone Elastomer Vaginal Gels for Sustained Release of Antiretroviral HIV Microbicides. Journal of Pharmaceutical Sciences 103:10.1002/jps.2014.103.issue-5, 1422-1432. [CrossRef]

16. Morrow Kathleen M., Fava Joseph L., Rosen Rochelle K., Vargas Sara, Shaw Julia G., Kojic E. Milu, Kiser Patrick F., Friend David R., Katz, and The Project LINK Study Team David F.. 2014. Designing Preclinical Perceptibility Measures to Evaluate Topical Vaginal Gel Formulations: Relating User Sensory Perceptions and Experiences to Formulation Properties. AIDS Research and Human Retroviruses 30:1, 78-91. [Abstract] [Full Text HTML] [Full Text PDF] [Full Text PDF with Links]

17. David R. Friend, Patrick F. Kiser. 2013. Assessment of topical microbicides to prevent HIV-1 transmission: Concepts, testing, lessons learned. Antiviral Research 99, 391-400. [CrossRef]

18. Phalguni Gupta, Carol Lackman-Smith, Beth Snyder, Deena Ratner, Lisa C. Rohan, Dorothy Patton, Bharat Ramratnam, Alexander M. Cole. 2013. Antiviral Activity of Retrocyclin RC-101, a Candidate Microbicide Against Cell-Associated HIV-1. AIDS Research and Human Retroviruses 29:2, 391-396. [Abstract] [Full Text HTML] [Full Text PDF] [Full Text PDF with Links]

19. Kathleen M. Morrow, Elizabeth E. Tolley, Alex Carballo-DieguezTopical Microbicide Acceptability 229-249. [CrossRef] 
20. Meredith R. Clark, David R. Friend. 2012. Pharmacokinetics and Topical Vaginal Effects of Two Tenofovir Gels in Rabbits. AIDS Research and Human Retroviruses 28:11, 1458-1466. [Abstract] [Full Text HTML] [Full Text PDF] [Full Text PDF with Links]

21. Phalguni Gupta, Deena Ratner, Ming Ding, Bruce Patterson, Lisa C. Rohan, Todd A. Reinhart, Velpandi Ayyavoo, Xioli Huang, Dorothy L. Patton, Bharat Ramratnam, Alexander M. Cole. 2012. Retrocyclin RC-101 Blocks HIV-1 Transmission Across Cervical Mucosa in an Organ Culture. JAIDS Journal of Acquired Immune Deficiency Syndromes 60, 455-461. [CrossRef]

22. Tanuja N Gengiah, Cheryl Baxter, Leila E Mansoor, Ayesha BM Kharsany, Salim. S Abdool Karim. 2012. A drug evaluation of $1 \%$ tenofovir gel and tenofovir disoproxil fumarate tablets for the prevention of HIV infection. Expert Opinion on Investigational Drugs 1-21. [CrossRef]

23. Vivek Agrahari, Bi-Botti C. Youan. 2012. Sensitive and Rapid HPLC Quantification of Tenofovir from Hyaluronic Acid-Based Nanomedicine. AAPS PharmSciTech 13, 202-210. [CrossRef]

24. Deborah Kacanek, Amanda Dennis, Nuriye Nalan Sahin-Hodoglugil, Elizabeth T. Montgomery, Neetha Morar, Sibongile Mtetwa, Busi Nkala, Jessica Phillip, Connie Watadzaushe, Ariane van der Straten, the MIRA Team. 2012. A Qualitative Study of Obstacles to Diaphragm and Condom Use in an HIV Prevention Trial in Sub-Saharan Africa. AIDS Education and Prevention 24, 54-67. [CrossRef]

25. Rebecca Giguere, Alex Carballo-Diéguez, Ana Ventuneac, Marina Mabragaña, Curtis Dolezal, Beatrice A. Chen, Jessica A. Kahn, Gregory D. Zimet, Ian McGowan. 2011. Variations in microbicide gel acceptability among young women in the USA and Puerto Rico. Culture, Health \& Sexuality 1-16. [CrossRef]

26. Amanda L Harrison, Stephen Henry, Radhia Mahfoud, Adam Manis, Aurelie Albertini, Yves Gaudin, Clifford A Lingwood, Donald R Branch. 2011. A novel VSV/HIV pseudotype approach for the study of HIV microbicides without requirement for level 3 biocontainment. Future Virology 6, 1241-1259. [CrossRef]

27. Rabeea F. Omar, Michel G. Bergeron. 2011. The future of microbicides. International Journal of Infectious Diseases 15, e656e660. [CrossRef]

28. Alex Carballo-Diéguez, Rebecca Giguere, Curtis Dolezal, Beatrice A. Chen, Jessica Kahn, Greg Zimet, Marina Mabragaña, ChengShiun Leu, Ian McGowan. 2011. "Tell Juliana”: Acceptability of the Candidate Microbicide VivaGel ${ }^{\circledR}$ and Two Placebo Gels Among Ethnically Diverse, Sexually Active Young Women Participating in a Phase 1 Microbicide Study. AIDS and Behavior . [CrossRef]

29. Ellen D. Mahan, Kathleen M. Morrow, John E. Hayes. 2011. Quantitative perceptual differences among over-the-counter vaginal products using a standardized methodology: implications for microbicide development. Contraception 84, 184-193. [CrossRef]

30. Rewa Kohli, Sharon Tsui, Sanjay Mehendale, Elizabeth Tolley. 2011. Indian married men's interest in microbicide use. AIDS Care 1-6. [CrossRef]

31. Lin Li, Suiyi Tan, Hong Lu, Lu Lu, Jie Yang, Hong Jin, Shuwen Liu, Shibo Jiang. 2011. Combinations of 3-Hydroxyphthalic Anhydride-Modified Ovalbumin With Antiretroviral Drug-Based Microbicide Candidates Display Synergistic and Complementary Effects Against HIV-1 Infection. JAIDS Journal of Acquired Immune Deficiency Syndromes 56, 384-392. [CrossRef]

32. Ian McGowan. 2011. Rectal Microbicides: Can We Make Them and Will People Use Them?. AIDS and Behavior 15, 66-71. [CrossRef]

33. David R. Friend. 2010. Pharmaceutical development of microbicide drug products. Pharmaceutical Development and Technology 15, 562-581. [CrossRef]

34. Sarah Martin, Kelly Blanchard, Chomnad Manopaiboon, Supaporn Chaikummao, Kate Schaffer, Barbara Friedland, Peter H. Kilmarx. 2010. Carraguard ${ }^{\circledR}$ Acceptability Among Men and Women in a Couples Study in Thailand. Journal of Women's Health 19:8, 1561-1567. [Abstract] [Full Text HTML] [Full Text PDF] [Full Text PDF with Links]

35. Lynn T Matthews, Jared M Baeten, Connie Celum, David R Bangsberg. 2010. Periconception pre-exposure prophylaxis to prevent HIV transmission: benefits, risks, and challenges to implementation. AIDS 24, 1975-1982. [CrossRef]

36. Susie Hoffman, Kate M. Morrow, Joanne E. Mantell, Rochelle K. Rosen, Alex Carballo-Diéguez, Fang Gai. 2010. Covert Use, Vaginal Lubrication, and Sexual Pleasure: A Qualitative Study of Urban U.S. Women in a Vaginal Microbicide Clinical Trial. Archives of Sexual Behavior 39, 748-760. [CrossRef]

37. Todd J. Johnson, Kavita M. Gupta, Judit Fabian, Theodore H. Albright, Patrick F. Kiser. 2010. Segmented polyurethane intravaginal rings for the sustained combined delivery of antiretroviral agents dapivirine and tenofovir. European Journal of Pharmaceutical Sciences 39, 203-212. [CrossRef]

38. Marjan Javanbakht, Ryan Murphy, Pamina Gorbach, Marc-André LeBlanc, Jim Pickett. 2010. Preference and practices relating to lubricant use during anal intercourse: implications for rectal microbicides. Sexual Health 7, 193. [CrossRef] 
39. Amanda E. Tanner, Katherine A. Roof, Barry P. Katz, Adrian Katschke, J. Dennis Fortenberry, Gregory D. Zimet. 2010. A comparison of young women. Sexual Health . [CrossRef]

40. Robert W. Buckheit, Karen M. Watson, Kathleen M. Morrow, Anthony S. Ham. 2010. Development of topical microbicides to prevent the sexual transmission of HIV. Antiviral Research 85, 142-158. [CrossRef]

41. Lisa Cencia Rohan, Alexandra B. Sassi. 2009. Vaginal Drug Delivery Systems for HIV Prevention. The AAPS Journal 11, 78-87. [CrossRef]

42. Astou Coly, Pamina M Gorbach. 2008. Microbicide acceptability research: recent findings and evolution across phases of product development. Current Opinion in HIV and AIDS 3, 581-586. [CrossRef] 